\title{
PREDICTION OF MECHANICAL PROPERTIES OF POLYCHLOROPRENE DURING THERMO-OXIDATIVE AGING
}

\author{
T. Ha Anh and T. Vu-Khanh* \\ Département de génie mécanique \\ Université du Québec/ École de technologie supérieure \\ Montréal, Québec, H3C 1K3, Canada
}

\begin{abstract}
The thermoxidative aging behavior of a polychloroprene (CR) has been investigated using the Mooney-Rivlin equation. During aging, both elastic constants $C_{1}$ and $C_{2}$ of the rubber increase, due to crosslink formation and decrease in flexibility of the structure network. The dependences of the mechanical properties on aging time and aging temperature are found to follow the Arrhenius relationship with similar activation energy.
\end{abstract}

\section{INTRODUCTION}

Degradation occurs in a wide variety of environments and service conditions and limits the service lifetime of many elastomers. For instance, in oxygen-containing environments, the mechanical strength of rubbers can be greatly affected by oxidation, especially at relatively high temperatures. In order to determine the resistance of a vulcanizate to oxidation, accelerated aging tests are used and most investigations have been focused on the change in chemical nature of the elastomer during extended exposure to heat, oxygen, ozone, and various other environments. During thermal aging, main-chain scission, crosslink formation and crosslink breakage can occur (Hamed et al. [1]). This study aims to foster the understanding of the variations in tensile behaviors of polychloroprene rubber (CR) caused by thermoxidative aging. CR is widely used in wire and cables sheathing applications due to its good resistance to weathering, ozone, abrasion, flame and oil (Bament et al. [2]). The major limitation with using CR is its poor aging resistance. CR rubbers show reasonably good oxidative aging resistance at up to $80^{\circ} \mathrm{C}$, but degradation becomes more pronounced when they are aged above $100^{\circ} \mathrm{C}$ (Fletcher [3]), leading to a higher probability of brittle fracture. The structure-property relationship is characterized by the Mooney-Rivlin equation:

$$
\sigma=2\left(\lambda-\frac{1}{\lambda^{2}}\right)\left(C_{1}+\frac{C_{2}}{\lambda}\right)
$$

where $\sigma$ is the stress applied, $\lambda$ is the extension ratio and $C_{1}$ and $C_{2}$ are material constants. According to Eqn (1), the plot of $\sigma / 2\left(\lambda-\lambda^{-2}\right)$ as a function of $1 / \lambda$ yields a straight line, from which $C_{1}$ can be obtained by extrapolating the linear portion of the curve to $\lambda^{-1}=0$, and $C_{2}$ from the slope of the linear portion. Eqn (1) has been used to analyze the effects of various environments on the tensile behavior of elastomers such as swelling (Allen et al. [4], Sombatsompop [5]), the presence of diluents during crosslinking (Gee [6]), etc. It has been suggested that the Mooney-Rivlin constants $C_{1}$ and $C_{2}$ are respectively associated with the network structure and the flexibility of the network. In molecular terms, the constant $C_{I}$ depends primarily on the crosslink density and is essentially independent of network swelling (Allen et al. [4], Mark

\footnotetext{
*Corresponding author: toan.vu-khanh@etsmtl.ca
} 
[7]). According to the kinetic or statistical theory of rubber elasticity (Treloar [8]), the degree of crosslinking can be determined as:

$$
N=\frac{2 C_{1}}{k T}
$$

in which $N$ is the number of chains in unit volume of the network, $k$ is Boltzmann's constant, and $T$ is the absolute temperature. $C_{2}$ has been suggested to be associated with intermolecular forces and flexibility between the polymer chains (Sombatsompop et al. [9]). This value increases with increasing proportion of rigid crosslinks (such as monosulfidic and carbon linkages) (Sombatsompop [10]), and degree of crosslinking ( $\mathrm{Yu}$ et al. [11]). However, the relationship between thermal aging and the constants $C_{1}$ and $C_{2}$ has not been investigated. In this study an attempt has been made to consider the effect of thermal aging on the variation of the MooneyRivlin constants $C_{l}$ and $C_{2}$ applied for a polychloroprene rubber (CR).

\section{EXPERIMENTAL}

The polychloroprene (neoprene) sheets, with a thickness of $1.6 \mathrm{~mm}$, were provided by Fairprene Industrial Products Co., USA. Thermal aging experiments were performed in a convection oven, Model B45 C40 (Gruenberg Electric Company Inc.) under various combinations of aging time and aging temperature. The tensile test was prepared according to the ASTM Standard D 412, using the Die C test method for tensile properties of elastomers. The tests were performed on an Instron Automatic Material Testing System, Model 1137, at a loading rate of $10 \mathrm{~mm} / \mathrm{min}$. The elongation was measured using a Laser Extensometer, Model MTS LX 500.

\section{RESULTS AND DISCUSSION}

The values of $C_{I}$ and $C_{2}$ for $\mathrm{CR}$ aged at various aging time and temperature are given in Table 1. It can be seen that both of $C_{1}$ and $C_{2}$ increase with aging time and aging temperature. From these results, the crosslink density is estimated by Eqn (2). By expressing Eqn (1) in terms of strain $\varepsilon$ $(=\lambda-1)$ and considering small $\varepsilon$, the ratio $\sigma / \varepsilon$ at infinitesimally small strain (i.e. the value of the tensile modulus $E$ ) can be determined by $6\left(C_{I}+C_{2}\right)$. For a comparison purpose, the Young modulus $E$ calculated from the initial slope of the tensile stress-strain curve is also reported. It can be seen that thermal aging increases the crosslink density of $\mathrm{CR}$ and this effect is more significant with increasing aging time and aging temperature. The value of $C_{2}$ seems also to increase with aging. This is probably due to the higher crosslink density causing closer molecular chains and, thus, an increase in intermolecular forces. It can be seen from Table 1 that $6\left(C_{I}+C_{2}\right)$ is almost equal to the tensile Young modulus $E$ calculated from the initial slope of the tensile stress-strain curve, suggesting that the general theory of large elastic deformations for rubber-like materials is valid. With prolonged aging or/and at higher aging temperatures, for example after 72 hours aged at $150^{\circ} \mathrm{C}$, a stage will be reached where most of the rubber at the surface has reacted with oxygen and forms an oxidized skin thus decreasing further penetration of oxygen into the bulk of the material. The surface became hard and the extensibility of the heterogeneously oxidized material was too small to permit an accurate determination of $C_{1}$ and $C_{2}$. This happened similarly to samples aged at $160^{\circ} \mathrm{C}$ after 39.5 hours as presented in Table 1. 
Table 1: Mooney-Rivlin coefficients, crosslinking degree, and Young modulus of CR after different thermal aging conditions.

\begin{tabular}{|c|c|c|c|c|c|c|}
\hline $\begin{array}{c}\text { Aging } \\
\text { temperature }\left({ }^{\circ} \mathrm{C}\right)\end{array}$ & $\begin{array}{c}\text { Aging time } \\
(\mathrm{h})\end{array}$ & $\begin{array}{c}\mathrm{C}_{1} \\
(\mathrm{kPa})\end{array}$ & $\begin{array}{c}\mathrm{C}_{2} \\
(\mathrm{kPa})\end{array}$ & $\begin{array}{c}\text { Crosslink density } \\
\mathrm{N}^{*} 10^{-26}\left(\mathrm{~m}^{-3}\right)\end{array}$ & $\begin{array}{c}6\left(\mathrm{C}_{1}+\mathrm{C}_{2}\right) \\
(\mathrm{Mpa})\end{array}$ & $\begin{array}{c}\mathrm{E} \\
(\mathrm{Mpa})\end{array}$ \\
\hline UNAGED & 0 & 169 & 443 & 0.82 & 3.67 & 3.41 \\
\hline & 12 & 192 & 407 & 0.93 & 3.59 & 3.51 \\
& 24 & 195 & 408 & 0.95 & 3.62 & 3.60 \\
& 48 & 199 & 413 & 0.97 & 3.67 & 3.69 \\
& 96 & 214 & 454 & 1.04 & 4.01 & 3.68 \\
& 168 & 299 & 541 & 1.45 & 5.04 & 4.84 \\
\hline \multirow{5}{*}{100} & 24 & 204 & 504 & 0.99 & 4.25 & 4.05 \\
& 48 & 243 & 619 & 1.18 & 5.17 & 4.74 \\
& 96 & 343 & 834 & 1.67 & 7.06 & 6.96 \\
& 168 & 588 & 1329 & 2.86 & 11.50 & 10.93 \\
\hline \multirow{5}{*}{130} & 16 & 212 & 459 & 1.03 & 4.03 & 4.25 \\
& 24 & 220 & 483 & 1.07 & 4.22 & 4.00 \\
& 48 & 293 & 607 & 1.42 & 5.40 & 5.14 \\
& 72 & 463 & 778 & 2.25 & 7.45 & 6.75 \\
& 112 & 680 & 1412 & 3.31 & 12.55 & 9.35 \\
& 144 & 1125 & 2177 & 5.47 & 19.81 & 17.31 \\
& 168 & 1186 & 3189 & 5.77 & 26.25 & 24.58 \\
\hline \multirow{3}{*}{140} & 24 & 345 & 786 & 1.68 & 6.78 & 6.53 \\
& 48 & 523 & 1221 & 2.54 & 10.46 & 10.43 \\
& 96 & 1129 & 2920 & 5.49 & 24.29 & 27.20 \\
\hline & 7 & 222 & 456 & 1.08 & 4.07 & 3.84 \\
& 17 & 379 & 543 & 1.84 & 5.54 & 4.96 \\
& 24 & 429 & 631 & 2.08 & 6.36 & 5.92 \\
& 40 & 615 & 1214 & 2.99 & 10.97 & 8.34 \\
& 48 & 740 & 1435 & 3.60 & 13.05 & 11.81 \\
& 72 & - & - & - & - & 31.26 \\
\hline & 28.5 & 425 & 835 & 2.07 & 7.56 & 7.28 \\
& 20 & 486 & 1104 & 2.36 & 9.54 & 8.83 \\
& 49 & 931 & 1482 & 4.52 & 14.48 & 12.36 \\
& 48 & - & - & - & - & 20.03 \\
& & - & - & - & - & 43.91 \\
\hline
\end{tabular}

From the experimental data, a kinetic equation of thermal degradation can be applied to obtain a relationship between these parameters and aging time and aging temperature. The rate of thermal degradation of a given property can be expressed using the Dakin's kinetic relation (Dakin [12]):

$$
\frac{d x}{d t}=k(T) f(x)
$$

where $x$ is the investigated property, $t$ is the thermal aging time, $k(T)$ is the rate constant of degradation, and $f(x)$ is a function of the degree of degradation. For the thermal degradation of a large number of polymeric materials, the temperature dependence of the rate constant $k(T)$ is often described by Arrhenius relation (Glasstone et al. [13]):

$$
k(T)=A \exp \left(-\frac{E_{a}}{R T}\right)
$$


in which $A$ is the pre-exponential factor, $E_{a}$ the activation energy, $R$ the gas constant, and $T$ the absolute temperature. The dependence of the investigated property as a function of aging time and aging temperature is deduced from the combination of Eqns (3) and (4):

$$
\frac{d x}{f(x)}=A \exp \left(-\frac{E_{a}}{R T}\right) d t
$$

During accelerated aging, oxygen diffusion and its consumption affect the crosslink density of the network. This subsequently leads to changes in hardness and tensile modulus of the material. Since the Mooney-Rivlin constants, $C_{1}$ and $C_{2}$, are related to the tensile modulus $\left(6\left(C_{1}+C_{2}\right)=E\right)$, the variations of these parameters with aging are expected to controlled by a thermal degradation process. Figures 1, 2, and 3 show the variations of $C_{I}, C_{2}$, and Young modulus $E$ as a function of aging time and aging temperature. The experimental data suggest that the increases of $C_{1}, C_{2}$, and $E$ with aging follow an exponential relation. Consequently, Eqn (3) deduces:

$$
f(x)=x
$$

Hence, after substituting the relation (6) into Eqn (5) and integrating, the following dependence of the properties $C_{1}, C_{2}$, and $E$ on aging time and aging temperature is obtained:

$$
x(t, T)=x_{o} \exp \left(A t \exp \left(-\frac{E_{a}}{R T}\right)\right)
$$

Table 2 shows the values of parameters $x_{o}, A$, and $E_{a}$ when using Eqn (7) to analyze the variation of $C_{1}, C_{2}$, and $E$ due to aging.

Table 2: Values of parameters $x_{o}, A$, and $E_{a}$ for investigated properties of CR

\begin{tabular}{|c|c|c|c|}
\hline Property & $\boldsymbol{x}_{\boldsymbol{o}}(\mathrm{kPa})$ & $\boldsymbol{A}\left(\right.$ hour $\left.^{-1}\right)$ & $\boldsymbol{E}_{\boldsymbol{a}}(\mathrm{kJ} / \mathrm{mol})$ \\
\hline $\boldsymbol{C}_{\boldsymbol{1}}$ & 192 & $6,01 \mathrm{E}+07$ & 74,9 \\
\hline $\boldsymbol{C}_{\boldsymbol{2}}$ & 399 & $2,26 \mathrm{E}+07$ & 71,8 \\
\hline $\boldsymbol{E}$ & 3232 & $4,94 \mathrm{E}+07$ & 74,3 \\
\hline
\end{tabular}

Eqn (7) is in good agreement with experimental results as shown in Figures 1-3 where the theoretical curves are also shown. The activation energies $E_{a}$ obtained are almost the same for $C_{l}$, $C_{2}$ and $E$, suggesting that these properties are controlled by similar thermo-oxidative aging processes with constant activation energies over the investigated range of aging temperatures. An extrapolation of these properties at unaged condition gives values of $C_{1}, C_{2}$ and $E$ to be $192 \mathrm{kPa}$, $399 \mathrm{kPa}$, and 3.2 Mpa respectively. These values are in agreement with the experimental measurement for unaged $\mathrm{CR}$ provided in Table 1. 

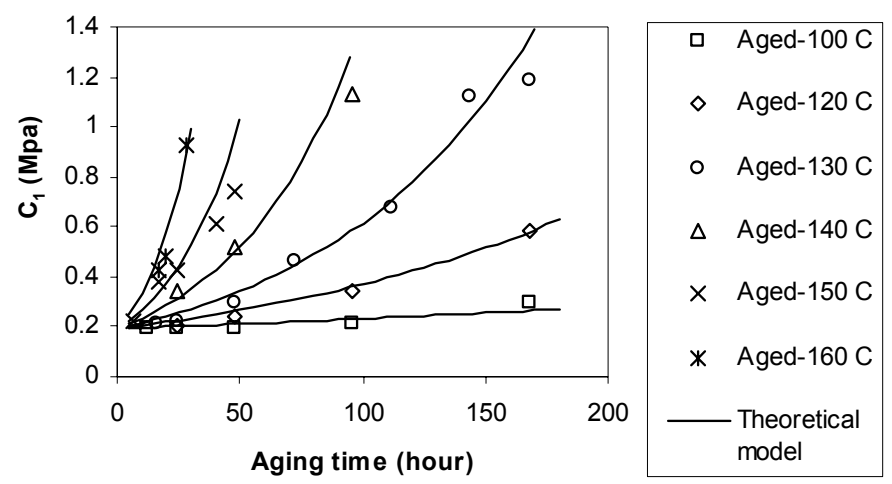

Figure 1: Variation of the constant $C_{l}$ of $\mathrm{CR}$ with aging time at various aging temperatures.
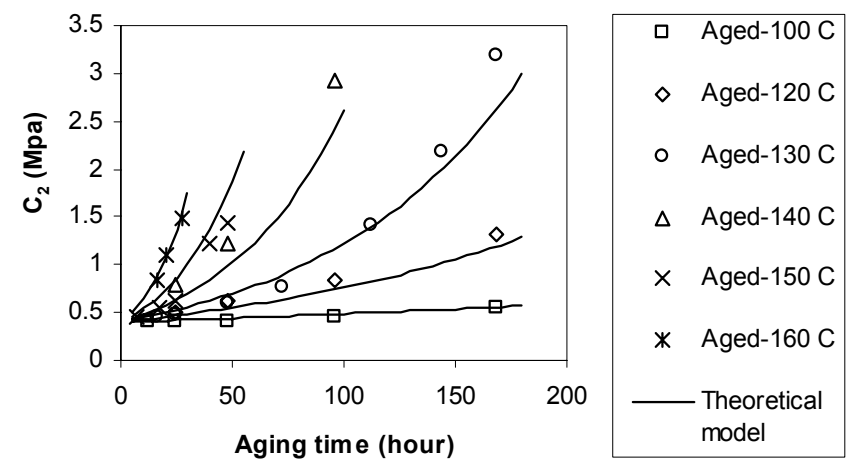

Figure 2: Variation of the constant $C_{2}$ of $\mathrm{CR}$ with aging time at various aging temperatures.
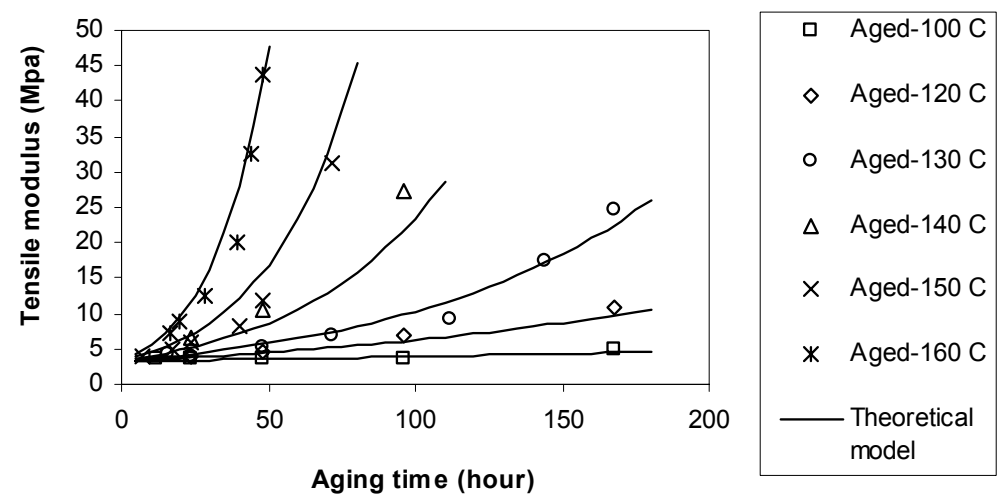

Figure 3: Variation of the tensile modulus of $\mathrm{CR}$ with aging time at various aging temperatures. 


\section{CONCLUSION}

The effects of thermo-oxidative aging on the tensile behaviors of $\mathrm{CR}$ have been investigated. Crosslink formation dominates during aging of $\mathrm{CR}$, leading to steady increases in the elastic constants of the Mooney-Rivlin equation. This is explained by a higher crosslink density causing closer molecular chains and, thus, an increase in intermolecular forces. During aging, the change in $C_{1}, C_{2}$ and $E$ is controlled by a similar thermo-oxidative process, which has the same constant activation energy over the investigated range of aging temperatures.

\section{REFERENCES}

[1] Hamed, G. R., and Zhao, J., "Tensile behavior after oxidative aging of gum and black-filled vulcanizates of SBR and NR", Rubber Chem. Technol., 72, pp. 721-730, 1999.

[2] Bament, J. C., and Pillow, J. G., in Developments in Rubber Technology-2, Wheelan, A. and Lee, K. S. (Eds), Applied Science Publishers Ltd., London, p. 147, 1981.

[3] Fletcher, W. P., in Rubber Technology and Manufacture, Blow, C. M., and Hepburn, C. (Eds), Butterworth Scientific, London., p. 121, 1982.

[4] Allen, G., Kirkham, M. J., Padget, J., and Price, C., "Thermodynamics of rubber elasticity at constant volume", Trans. Faraday Soc., 67, pp. 1278-1292, 1971.

[5] Sombatsompop, N., "Practical concerns regarding the use of the Mooney-Rivlin equation to assess degree of crosslinking of swollen rubber vulcanisates", Polym. \& Polym. Comp., 7, pp. 41-44, 1999.

[6] Gee, G., "The present status of the theory of rubber elasticity*1", Polymer, 7, pp. 373-385, 1966.

[7] Mark, J. E., "Constants $2 \mathrm{C}_{1}$ and $2 \mathrm{C}_{2}$ in phenomenological elasticity theory and their dependence on experimental variables", Rubber Chem. Technol., 48, pp. 495-512, 1975.

[8] Treloar, L. R. G., The Physics of Rubber Elasticity, 3rd. Ed., Oxford University Press, London, 1975.

[9] Sombatsompop, N., and Christodoulou, K. J., "Penetration of Aromatic Hydrocarbons into Natural Rubber", Polym. \& Polym. Compos., 5, pp. 377-386, 1997.

[10] Sombatsompop, N., "Investigation of Swelling Behavior of NR Vulcanizates", Polym.-Plast. Technol. Eng., 37, pp. 19-39, 1998.

[11] Yu, C. U., and Mark, J. E., "Specific Solvent Effects in Swollen Polymer Networks", Rubber Chem. Technol., 47, pp. 1151-1159, 1974.

[12] Dakin, T. W., "Electrical Insulation Deterioration”, Electrotechnology, 66, pp. 123-130, 1960.

[13] Glasstone, S., Laidler, K. J., and Eyring, H., The Theory of Rate Processes, McGraw-Hill Book Co., New York, 1941. 